\section{Significance of early detection of oral malignant melanoma in improving prognosis}

Dear Editor,

The oral malignant melanoma (OMM) is a rare disease that accounts for $0.8 \%$ of all melanomas, $8 \%$ of head and neck melanomas and up to $0.5 \%$ of all oral malignancies. The OMM usually presents as a pigmented lesion with irregular borders, uneven surface characteristics, and distinctive color. Generally, it is seen on the maxillary gingiva of males, however our patient was a middle aged male with pigmentation and growth over the left buccal mucosa; whose biopsy report was oral primary malignant melanoma [Figure 1]. OMM was previously considered as a lethal disease. In recent times there is adequate literature that explains the biological nature and behavior of the disease. OMM frequently display unpredictable pathophysiological behavior. Late detection contributes to the dismal prognosis.

OMM has been known for decades, but lack of adequate data and systematic studies attribute to its complexity. Many researchers, from the time of Weber and Lincoln in 1885 have attempted to solve the mystery. In addition, further studies were carried out to help generate guidelines that could minimize the mortality and boost social awareness. Currently, global climatic change is a major source for ultraviolet radiation exposure and increasing trend of sun beds; which emits ultraviolet radiation to produce a cosmetic brunette. ${ }^{[1]}$ That is why worldwide occurrence of freshly diagnosed melanomas is observed up to $3-8 \%$ and is increasing day by day. Mucosal melanomas are characterized by an aggressive biological behavior leading to a 5-year survival rate of less than $25 \% .{ }^{[2]}$ On the other hand, the etiological aspect for mucosal melanoma varies from cutaneous, since it is not directly correlated to ultraviolet radiation. Some of the causes of mucosal melanoma are; ill-fitting dentures, betel nut chewing, tobacco usage, formaldehydes exposures, amalgam tattoo due to iatrogenic deposit of dental amalgam, and nevi. ${ }^{[3]}$ Literature has well-evidenced that at some stage in

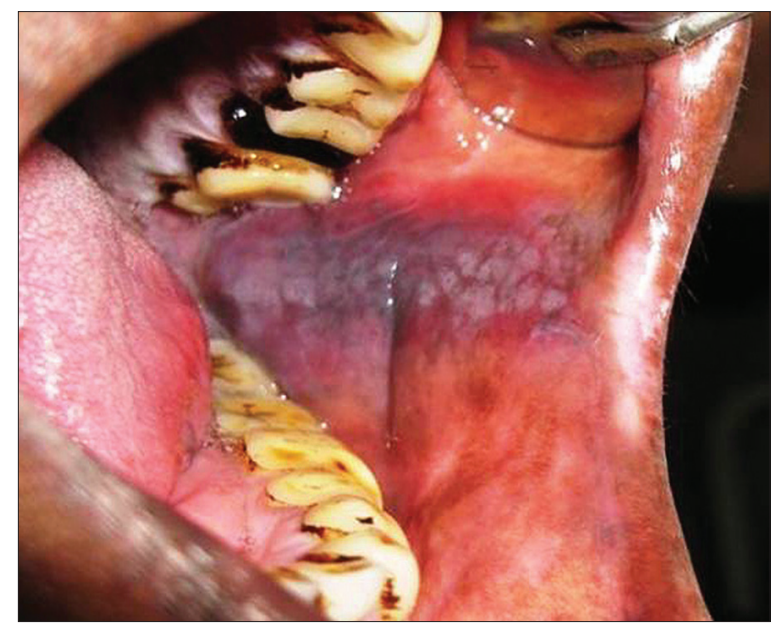

Figure 1: Oral primary malignant melanoma of buccal mucosa embryologic development, melanocytes travel from the neural crest into epithelial lining of skin and in the developed skin, they inhabit in basal epithelial layer. Likewise, the melanocytes develop in basal layer of oral epithelium and proliferate; as it is encountered with cytotoxic stimulant. ${ }^{[4]}$ Even if dendritic cells derived from neural crest produce the melanocytes, the exact mechanism of proliferation of these cells in melanoma is not known. OMM represents variety of morphologic and microscopic distinctiveness and lack of pain is one of the reasons of delay in its early detection and medical intervention. ${ }^{[5,6]}$ Most of the clinical characteristics of oral melanomas resemble cutaneous and other pigmented lesions like; dark brown or black color, irregular surface and asymmetrical margins, etc. Thus, the pigmented lesions of oral cavity; which does not possess clinical specificity should be viewed with suspicion. It should be differentiated from other oral pigmented lesions; including drug pigments, smoke-related melanosis, melanotic macule, Kaposi's sarcoma, physiologic or racial pigmentation, and nevus and melanoacanthoma. About $15 \%$ of the melanomas are non-pigmented and typically red lesions, thus presenting as amelanotic melanoma that looks like some oral red lesions. ${ }^{[7]}$ This letter in an effort to draw the attention of researchers towards imperative role of early diagnosis and treatment planning that could successfully prevent progression and improve prognosis.

Sridevi Kaul, Prince Kumar' Departments of Prosthodontics, Sudha Rustagi College of Dental Studies \& Research, Faridabad, 'Shree Bankey Bihari Dental College and Research Centre, Ghaziabad, India

Correspondence to: Dr. Prince Kumar,

E-mail: princekumar@its.edu.in

\section{References}

1. Benoist LB, van Looij MA. Images in clinical medicine. Melanoma of the oral cavity. N Engl J Med 2013;368:e 14.

2. Sharma N. Primary oral malignant melanoma: Two case reports and review of literature. Case Rep Dent 2012;97:53-8.

3. Bentham G, Aase A. Incidence of malignant melanoma of the skin in Norway, 1955-1989: Association with solar ultraviolet radiation, income and holidays abroad. Int J Epidemol 1996;25:1132-8.

4. Mhapuskar A, Umarji H, Jain N, Behere R, Aditya A. Intra-oral malignant melanoma: A case report and review of the literature. $N$ Z Dent J 2012; 108:102-4.

5. Ardekian L, Rosen DJ, Peled M, Rachmiel A, Machtei EE, el Naaj IA, et al. Primary gingival malignant melanoma. Report of 3 cases. J Periodontol 2000;71:117-20.

6. Bhullar RP, Bhullar A, Vanaki SS, Puranik RS, Sudhakara M, Kamat MS. Primary melanoma of oral mucosa: A case report and review of literature. Dent Res J (Isfahan) 2012;9:353-6.

7. Mohan M, Sukhadia VY, Pai D, Bhat S. Oral malignant melanoma: Systematic review of literature and report of two cases. Oral Surg Oral Med Oral Pathol Oral Radiol 2012;12:220-9.

\begin{tabular}{|l|l|}
\hline \multicolumn{2}{|c|}{ Access this article online } \\
\hline Quick Response Code: & Website: \\
\hline & www.sajc.org \\
\cline { 2 - 2 } & \\
\hline
\end{tabular}

